\title{
Malaysian validation of a sociopolitical control scale for youth
}

\begin{abstract}
Empowerment is a process by which people and groups gain control over their lives and environments. The emotional component of psychological empowerment has been assessed using a measure of sociopolitical control. Prior research has measured sociopolitical control as a construct with two dimensions: (a) leadership competence and (b) policy control. This study tested the factor structure of the Sociopolitical Control Scale for Youth (SPCS-Y) in a sample of Malaysian secondary school students $(n=364$; mean age $=16)$ involved in 3 afterschool programs. Analyses found support for the bidimensional factor structure by using factor loadings and modification indices to reduce the scale from 17 to 8 items. Participants with higher scores on both dimensions of the SPCS-Y were found to have higher levels of psychological sense of community, school connectedness, and perceived agency. These findings provide support for a measure of youth empowerment in Malaysia and build on recent findings from other nations.
\end{abstract}

Keyword: Malaysian validation; Sociopolitical control scale; Youth; Malaysia 